\title{
THE EFFECTS OF SYNTHETIC ANGIOTENSIN AND NORADRENALINE ON BLOOD PRESSURE AND RENAL FUNCTION
}

\author{
BY \\ E. G. MCQUEEN and R. B. I. MORRISON* \\ From the Department of Medicine, University of Otago, Dunedin, New Zealand \\ Received February 26, 1960
}

The synthesis of angiotensin (Schwarz et al., 1957, Rittel et al., 1957) has enabled sufficient amounts of this extremely powerful vasopressor substance to be made available for clinical study. $\dagger$ Its potential value in clinical conditions makes it imperative to have an adequate knowledge of its hæmodynamic effects as a preliminary to its use. Angiotensin is likely to have its most effective role in management of states accompanied by severe hypotension. In the treatment of such conditions noradrenaline is at present the most effective agent, and in this study a comparison has been made in subjects with normal pressures of some renal and hæmodynamic effects of the two substances.

\section{METHOD}

A comparison was made of the effects of noradrenaline and angiotensin on renal function in 8 male volunteers. None of these had a past history of renal disease. Breakfast was withheld and an adequate rate of urine flow maintained with oral fluids. Care was taken not to induce nausea.

After an initial loading dose of $30 \mathrm{ml}$. of $10 \%$ inulin and $6 \mathrm{ml}$. of $50 \%$ diodrast, a constant blood level of these substances was maintained by an intravenous infusion of $240 \mathrm{ml}$. normal saline containing $70 \mathrm{ml}$. inulin and $14 \mathrm{ml}$. diodrast, at 60 drops a minute. The control value was taken as the average of the first two clearance periods.

Using a mechanical constant-flow syringe a solution of either noradrenaline or angiotensin was infused via a needle in the rubber tubing of a standard drip set. The concentrations used were noradrenaline, $160-320 \mu \mathrm{g} . / \mathrm{ml}$., and angiotensin, $40-60 \mu \mathrm{g} . / \mathrm{ml}$. The rate of flow from the syringe was adjusted to give similar hypertensive responses with both drugs. The order of giving the drugs was reversed in consecutive subjects.

Two further clearance periods were obtained during the administration of each drug, sufficient time being allowed for equilibration between each set of clearances. Serial plasma samples were collected from a vein in the opposite arm.

Inulin was estimated by the Roe et al. (1949) colorimetric method, while Alpert's (1941) titration method was used to estimate diodrast. The urinary sodium was measured by flame photometry. Proteinuria was examined for with sulphosalicylic acid.

The values for gomerular filtration rate, renal plasma flow, and sodium excretion have been expressed as units/1.73 m. ${ }^{2}$ surface area (determined from Dubois' nomogram). Blood pressure values were obtained by averaging the levels during the period of drug action. The rate of infusion of the drugs was calculated from the amount delivered by the mechanical syringe.

In the second part of the study the effects of noradrenaline and angiotensin on peripheral veins were observed in 10 male volunteers.

* In receipt of a grant from the Medical Research Council (N.Z.).

$\dagger$ The angiotensin II (hypertensinII vals octapeptide) used in this study was most generously donated by Messrs. Ciba Ltd., Basle. 
Normal saline was infused via a standard "venopak" drip set and a 21 gauge needle into a vein on the back of the hand. The drip rate was fixed initially at 60 drops a minute. Noradrenaline or angiotensin was introduced into the infusion at a constant rate by the mechanical syringe. The concentrations used were: noradrenaline $240 \mu \mathrm{g} . / \mathrm{ml}$., angiotensin $60 \mu \mathrm{g} . / \mathrm{ml}$. Again the order of giving the drugs was reversed in consecutive subjects. Their effects on blood pressure and drip rate were observed at minute intervals. In the case of angiotensin, administration was continued until it was clear that no further reduction in drip rate was likely to occur. With noradrenaline, administration was continued either until a steady state had been reached or until it was impracticable to continue by reason of extreme venospasm. The drugs were then stopped and the drip rate allowed to recover. The recovery rate was taken as that at which no further recovery of drip rate took place without adjustment of the drip. The initial, highest, and recovery levels of the blood pressure, and the initial, lowest, and recovery levels of the drip rate were recorded.

\section{RESULTS}

Effects on Renal Function and Blood Pressure

In 8 healthy men an equivalent hypertensive response was obtained using a continuous infusion of either noradrenaline or angiotensin (Tables I and II). From the mean infusion rates, angiotensin

TABLE I

A Comparison of the Effects of Noradrenaline and Synthetic Angiotensin II on Renal Function and Blood Pressure in 8 Healthy Men (Mean tStandard Deviation)

\begin{tabular}{|c|c|c|c|c|c|c|c|}
\hline & $\begin{array}{c}\text { Rate of } \\
\text { infusion } \\
(\mu . \mathrm{g} / \mathrm{min} .)\end{array}$ & $\underset{(\mathrm{mm} . \mathrm{Hg} .)}{\mathrm{BP}}$ & $\begin{array}{l}\text { Pulse } \\
\text { rate/min. }\end{array}$ & 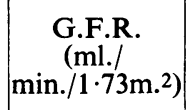 & $\begin{array}{c}\text { R.P.F. } \\
\text { (mi.j/ } \\
\min . / 1 \cdot 73 \mathrm{~m} .2)\end{array}$ & $\begin{array}{l}\text { Filtration } \\
\text { fraction }\end{array}$ & $\begin{array}{l}\mathrm{Na} \text { excretion } \\
(\mu \mathrm{eq} . / \\
\left.\mathrm{min} . / 1 \cdot 73 \mathrm{~m} .{ }^{2}\right)\end{array}$ \\
\hline Control & & $\frac{119 \cdot 6 \pm 13 \cdot 7}{78 \cdot 3 \pm 7 \cdot 8}$ & $68 \cdot 5 \pm 4 \cdot 4$ & $117 \cdot 6 \pm 19 \cdot 1$ & $711 \pm 263$ & $0 \cdot 189 \pm 0.068$ & $288 \pm 124$ \\
\hline Noradrenaline & $9 \cdot 7 \pm 3 \cdot 2$ & $\frac{140 \cdot 1 \pm 13 \cdot 6}{93 \cdot 9 \pm 8 \cdot 6}$ & $68 \cdot 0 \pm 6 \cdot 6$ & $112 \cdot 6 \pm 25 \cdot 1$ & $575 \pm 164$ & $0.207 \pm 0.059$ & $171 \pm 129$ \\
\hline Angiotensin & $1 \cdot 72 \pm 0 \cdot 41$ & $\frac{140 \cdot 8 \pm 12 \cdot 3}{97 \cdot 6 \pm 8 \cdot 4}$ & $61 \cdot 5 \pm 6 \cdot 1$ & $82 \cdot 6 \pm 22 \cdot 1$ & $503 \pm 169$ & $0.198 \pm 0.078$ & $49 \pm 23$ \\
\hline
\end{tabular}

G.F.R. = Glomerular filtration rate. $\quad$ R.P.F. $=$ Renal plasma flow.

TABLE II

Statistical Relationships of the Results in Table I

\begin{tabular}{|c|c|c|c|c|c|c|}
\hline & $\underset{\text { pressure }}{\text { Blood }}$ & Pulse & G.F.R. & R.P.F. & $\begin{array}{l}\text { Filtration } \\
\text { fraction }\end{array}$ & $\begin{array}{l}\text { Sodium } \\
\text { excretion }\end{array}$ \\
\hline $\begin{array}{l}\text { Control } \\
v \text {. } \\
\text { Noradrenaline }\end{array}$ & $P<0.001$ & N.S. & N.S. & $0.05>P>0.02$ & N.S. & $0.01>P>0.001$ \\
\hline $\begin{array}{l}\text { Control } \\
v . \\
\text { Angiotensin }\end{array}$ & $P<0.001$ & $0.02>P>0.01$ & $P<0.001$ & $0.05>P>0.02$ & N.S. & $P<0.001$ \\
\hline $\begin{array}{l}\text { Noradrenaline } \\
v . \\
\text { Angiotensin }\end{array}$ & N.S. & $0.02>P>0.01$ & $0.05>P>0.01$ & N.S. & N.S. & $0.01>P>0.001$ \\
\hline
\end{tabular}

NS $=$ Not significant 
$1.72 \mu \mathrm{g} . / \mathrm{min}$., noradrenaline $9 \cdot 7 \mu \mathrm{g}$./min., angiotensin was apparently 5.6 times as potent. Confirmation of this potency ratio was inferred from the hypertensive response to these two drugs when their effects on peripheral veins were being examined. Using a constant concentration ratio of noradrenaline to angiotensin of $4: 1$, the hypertensive response to noradrenline was less than that to angiotensin (Table III).

TABLE III

The Effects on Blood Pressure of Intravenous Introduction at the Same Rate of Noradrenaline and ANGiotensin Solutions in Concentration Ratio of 4:1. 10 Male SubJeCts

\begin{tabular}{l|c|c|c}
\hline & \multicolumn{2}{|c}{ Blood pressure: mean and standard deviation } \\
\hline & Initial & Highest & Recovery \\
\hline $\begin{array}{c}\text { Noradrenaline } \\
240 \mu \mathrm{g} . / \mathrm{ml} .\end{array}$ & $\frac{125 \cdot 0 \pm 6 \cdot 6}{77 \cdot 8 \pm 4 \cdot 5}$ & $\frac{137 \cdot 8 \pm 7 \cdot 5}{97 \cdot 0 \pm 5 \cdot 1}$ & $\frac{125 \cdot 6 \pm 9 \cdot 6}{76 \cdot 3 \pm 6 \cdot 4}$ \\
\hline $\begin{array}{c}\text { Angiotensin } \\
60 \mu \mathrm{g} . / \mathrm{ml} .\end{array}$ & $\frac{126 \cdot 4 \pm 9 \cdot 7}{79 \cdot 1 \pm 5 \cdot 5}$ & $\frac{142 \cdot 6 \pm 9 \cdot 9}{105 \cdot 6 \pm 7 \cdot 5}$ & $\frac{125 \cdot 2 \pm 8 \cdot 3}{78 \cdot 5 \pm 5 \cdot 0}$ \\
\hline
\end{tabular}

A comparison of the effects of noradrenaline and angiotensin on the glomerular filtration rate, renal plasma flow, sodium excretion, and pulse rate, for an equivalent degree of hypertension, is shown in Table I. One renal plasma flow estimation was discarded.

From a mean control value of $117.6 \mathrm{ml} . / \mathrm{min}$., noradrenaline produced a non-significant reduction in the glomerular filtration rate (to $112.6 \mathrm{ml} . / \mathrm{min}$.). With angiotensin, the reduction was greater, to $82.6 \mathrm{ml} . / \mathrm{min}$. $(\mathrm{P}<0.001)$. The difference in the values for the two drugs was significant at the level $0.05>\mathrm{P}>0.02$.

Noradrenaline and angiotensin both produced significant reductions in the renal plasma flow $(0.05>P>0.02)$. Although the mean value for angiotensin was some $70 \mathrm{ml} . / \mathrm{min}$. lower, the values of R.P.F. while on the two drugs were not significantly different. The filtration fraction showed a non-significant rise with both drugs.

From a mean value of $288 \mu \mathrm{eq}$./min. the reduction in sodium excretion caused by angiotensin (to $49 \mu \mathrm{eq} . / \mathrm{min}$.) was much greater than that produced by noradrenaline (to $171 \mu \mathrm{eq} . / \mathrm{min} ., 0.01>$ P>0.001).

No proteinuria was detected during the administration of either drug.

These findings indicate that angiotensin produced a greater reduction in renal function than did noradrenaline. This was indeed suggested during the course of the experiments when the urine volumes were noticeably lower during the collection periods while on angiotensin.

The mean pulse rate did not alter with noradrenaline but fell with angiotensin.

\section{Effects on Peripheral Veins}

In a further $10 \mathrm{men}$, the effects of noradrenaline and angiotensin on peripheral veins were examined (Tables IV and V). In the concentrations used, angiotensin produced a significantly higher blood pressure than did noradrenaline (systolic $0.02>P>0.01$; diastolic $P<0.001$ ) (Table III). During this period the drip rate fell with angiotensin to a mean of $48 \mathrm{drops} / \mathrm{min}$., while noradrenaline reduced it to a mean of 19 drops/min.-the difference being highly significant $(P<0.001)$. This difference would have been greater still if the drip rate in all cases on noradrenaline had been allowed to reach equilibrium. However, when a good response was observed it was not felt justified to carry on the infusion any longer. After stopping the drugs the blood pressure returned to near control levels. A typical response is illustrated in Fig. 1. 
TABLE IV

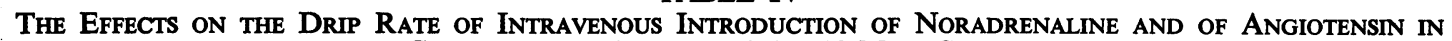
Concentration Ratio of 4:1. 10 Male SubJects

\begin{tabular}{l|c|c|c}
\hline & \multicolumn{2}{|c}{ Drip rate. } & Mean \pm standard deviation \\
\hline & Initial & Lowest & Recovery \\
\hline Noradrenaline & $61 \cdot 4 \pm 1 \cdot 5$ & $19 \cdot 2 \pm 9 \cdot 1$ & $53 \cdot 2 \pm 9 \cdot 8$ \\
Angiotensin & $60 \cdot 6 \pm 1 \cdot 6$ & $48 \cdot 3 \pm 10 \cdot 6$ & $57 \cdot 6 \pm 3 \cdot 8$ \\
\hline
\end{tabular}

TABLE V

Statistical Relationships Of THe Results in TAbles III and IV

\begin{tabular}{|c|c|c|c|c|c|c|}
\hline & $\begin{array}{c}\text { Control } \\
v . \\
\text { Noradrenaline }\end{array}$ & $\begin{array}{c}\text { Control } \\
v \text {. } \\
\text { Angiotensin }\end{array}$ & $\begin{array}{c}\text { Noradrenaline } \\
v . \\
\text { Angiotensin }\end{array}$ & $\begin{array}{c}\text { Control } \\
v . \\
\text { Recovery } \\
\text { (Noradrenaline) }\end{array}$ & $\begin{array}{c}\text { Control } \\
v . \\
\text { Recovery } \\
\text { (Angiotensin) }\end{array}$ & $\begin{array}{c}\text { Recovery } \\
\text { (Noradrenaline) } \\
v . \\
\text { Recovery } \\
\text { (Angiotensin) }\end{array}$ \\
\hline Blood pressure & $P<0.001$ & $P<0.001$ & $\begin{array}{c}\text { (Systolic) } \\
0.02>P>0.01 \\
\text { (Diastolic) } \\
P<0.001\end{array}$ & N.S. & N.S. & N.S. \\
\hline Drip rate & $P<0.001$ & $0.01>P>0.001$ & $P<0.001$ & $0.05>P>0.02$ & $0.05>P>0.02$ & N.S. \\
\hline
\end{tabular}

NS $=$ Not significant.

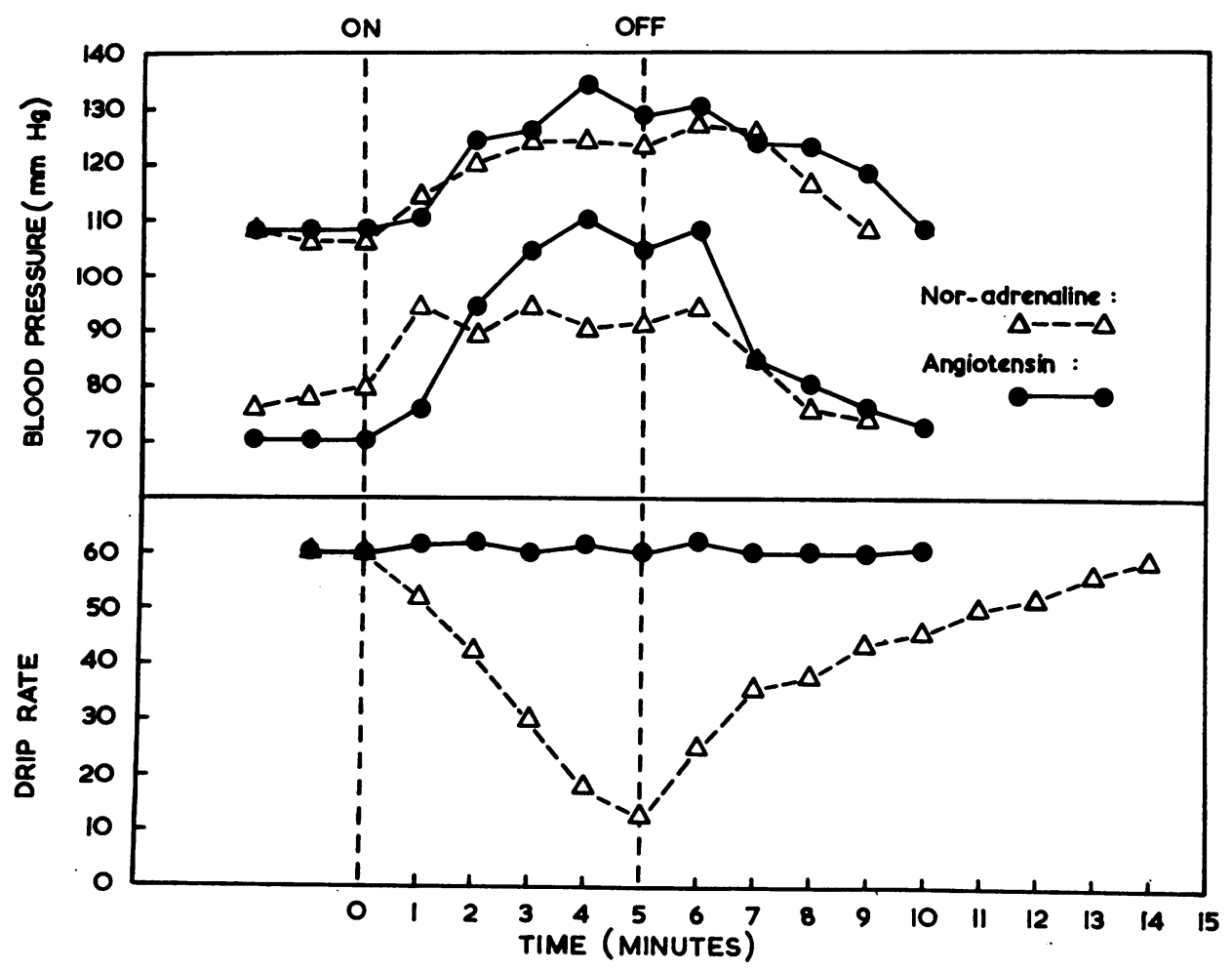

FIG. 1.-A comparison of the effects of a constant infusion of noradrenaline $(240 \mu \mathrm{g} . / \mathrm{ml}$. $)$ and of angiotensin $(60 \mu \mathrm{g} . / \mathrm{ml}$.) in raising blood pressure and in producing peripheral venospasm in a normal subject. 
The recovery drip rates failed to return to the control values following either drug, but there was no significant difference between them.

Nearly all subjects felt uncomfortable and vaguely uneasy during the noradrenaline infusion. Pallor was often quite striking and associated with cold perspiring extremities. On the other hand, although some developed slight pallor, cool extremities, mild apprehension, and tightness of the scalp, others did not realize they were receiving angiotensin.

The hypertensive effects of both drugs disappeared within a few minutes of stopping their infusion.

\section{DISCUSSION}

The substance now called angiotensin, a compromise name agreed on by Page and BraunMenendez for the original "angiotonin" of Page and "hypertensin" of Braun-Menendez, has been known for 20 years (Braun-Menendez et al., 1939; Page and Helmer, 1940) to be the vasopresser polypeptide formed by the action of renin on renin substrate (hypertensinogen) normally present in the plasma. Later it was shown (Skeggs et al., 1954) that this substance exists in two forms, a decapeptide, now referred to as angiotensin I and an octapeptide (angiotensin II), the latter, the active pressor substance, being produced from the former by a converting enzyme again normally present in the blood. The amino acid structure (of the decapeptide) was first elucidated by Elliot and Peart (1956) and synthesis of the octapeptide achieved by Schwarz et al. (1957) and by Rittel et al. (1957).

Angiotensin II is an extremely active pressor substance having a direct vasoconstrictor effect. With the development of the pure synthetic substance an accurate assessment of its activity became possible and it has proved to be even more active than noradrenaline (Meier et al., 1958). The possibility of using it as a vasopressor substance clinically is therefore of considerable interest.

In the management of severe hypotensive shock, noradrenaline has often proved life saving, particularly following coronary occlusion. There are however a number of disadvantages associated with its use. The concentration may have to be progressively increased because of apparently decreasing sensitivity, and, after a prolonged period of administration, "dependence" on the drug may be established so that its withdrawal becomes a difficult and tedious process. Additionally, the induction of local vaso-constriction and risk of skin necrosis when noradrenaline is given into a peripheral vein necessitates its administration into a large vein, preferably even the superior or inferior vena cava.

A vasopressor substance that could be used as an alternative to noradrenaline when unresponsiveness to the latter had developed would be of great value, particularly if it could be given safely into a peripheral vein.

In our experiments angiotensin given by continuous injection was found to have a considerably greater vasopressor activity than noradrenaline. In one series of observations, those dealing with renal function, the ratio of noradrenaline to angiotensin for an almost exactly equivalent rise in blood pressure was 5.6:1. In the other series, noradrenaline, given at a rate four times greater than that of angiotensin produced a significantly lesser pressor response. Bumpus et al. (1958), using biological assay methods, found that synthetic angiotensin was 4-8 times as active as noradrenaline. Recently (Finnerty et al., 1959), the hæmodynamic effects of angiotensin were observed to be some 10 times greater than those produced by noradrenaline in a group of normal subjects. Angiotensin had therefore an extremely active vasopressor effect and this was maintained for periods of up to an hour.

The rise in blood pressure was however accompanied by a very significant diminution in renal function. Reports of the effects of renin and of biological angiotensin on renal function were somewhat conflicting (Braun-Menendez, 1956). However, there is uniform evidence of depression of renal function by synthetic angiotensin in human subjects (Bock et al., 1958).

In our own observations glomerular filtration rate, renal plasma flow, urine flow and particularly sodium excretion were markedly diminished during the course of the infusion. Noradrenaline 
has been shown to produce a considerable reduction in renal plasma flow with little alteration in the glomerular filtration rate (Barnett et al., 1950). We have confirmed this, but in the same subjects, with the much lower dosage of angiotensin necessary to produce an hypertensive response equivalent to that of noradrenaline, we have found that angiotensin caused a much greater depression of renal function. However, Finnerty et al. (1959) report that a continuous 26-hour infusion of angiotensin in three young subjects did not produce any decrease in urine output.

Proteinuria, often a feature of natural angiotensin or renin infusion, did not occur in our obsevations.

It must be emphasized that these studies were performed on normal subjects with initially normal blood pressures. It is quite possible that the direct effects on renal function in patients suffering from severe hypotension may be outweighed by the improvement resulting from elevation of the blood pressure. However, the direct effects are clearly greater than those of noradrenaline, and, in a situation where renal function may already be critically interfered with, the greater impairment induced directly by angiotensin would seem to require some special reason for its employment, as for instance, unresponsiveness to noradrenaline.

The equally clearly smaller effect of angiotensin than of noradrenaline on peripheral veins is an interesting reflection of the variation in responsiveness to different vasopressor agents of vascular muscle in different situations. It also offers for angiotensin one practical advantage over noradrenaline, in suggesting that it may, if necessary, be administered into a peripheral instead of a central vein. Care must be taken however to avoid extravasation of the solution outside the vein as prolonged local ischæmia may result.

\section{SUMMARY}

The effects of synthetic angiotensin II on blood pressure and renal function have been investigated in a group of normal subjects and compared with those of noradrenaline. Angiotensin proved considerably more potent in raising blood pressure but was associated with a greater depression of renal function. On the other hand venospasm was less marked with angiotensin than with noradrenaline.

Synthetic angiotensin II deserves further study for its use in hypotension. The decrease in renal function found in subjects with a normal pressure will require evaluation.

We wish to acknowledge the advice and criticism of Sir Horace Smirk in conducting this study.

\section{REFERENCES}

Alpert, L. K. (1941). Johns Hopk. Hosp. Bull., 68, 522.

Barnett, A. J., Blackett, R. B., Depoorter, A. E., Sanderson, P. H., and Wilson, G. M. (1950). Clin. Sci., 9, 151.

Bock, K. D., Dengler, H., Krecke, H. J., and Reickel, G. (1958). Klin. Wschr., 36, 808.

Braun-Menendez, E., Fasciola, J. C., Leloir, F., and Munoy, J. M. (1939). Rev. Soc. argent. Biol., $15,420$.

- (1956). Pharmacol. Rev., 8, 25.

Bumpus, F. M., Schwarz, H., and Page, I. H. (1958). Circulation, 17, 664.

Elliot, D. F., and Peart, W. S. (1956). Nature, 177, 527.

Finnerty, F. A., Massare, G. D., Sigda, F. J., and Tuckman, V. (1959). Circulation, $20,694$.

Meier, R., Tripod, J., and Studer, A. (1958). Arch. int. Pharmacodyn., 117, 185.

Page, I. H., and Helmer, O. H. (1940). J. exp. Med., 71, 29.

Rittel, W., Iselin, B., Kappeler, H., Riniker, B., and Schwyzer, R. (1957). Helv. Chim. Acta, $40,614$.

Roe, J. H., Epstein, J. H., and Goldstein, N. P. (1949). J. biol. Chem., 178, 840.

Schwarz, H., Bumpus, F. M., and Page, I. H. (1957). J. Amer. chem. Soc., 79, 5697.

Skeggs, L. T., Marsh, W. H., Kahn, J. R., and Shumway, N. P. (1954). J. exp. Med., $99,275$. 